\title{
Capsicum Protects Against Rotenone-Induced Toxicity in Mice Brain Via Reduced Oxidative Stress and 5-Lipoxygenase Activation
}

\author{
Omar M.E. Abdel-Salam ${ }^{1}$, Amany A Sleem², Eman R. Youness ${ }^{3}$, Noha N. Yassen ${ }^{4}$, Nermeen \\ Shaffie $^{4}$, Sayed A. El-Toumy ${ }^{5 *}$
}

${ }^{1}$ Department of Toxicology and Narcotics, National Research Centre, Cairo, Egypt

${ }^{2}$ Department of Pharmacology, National Research Centre, Cairo, Egypt

${ }^{3}$ Department of Medical Biochemistry, National Research Centre, Cairo, Egypt

${ }^{4}$ Department of Pathology, National Research Centre, Cairo, Egypt

${ }^{5}$ Department of Chemistry of Tannins, National Research Centre, Cairo, Egypt

*Corresponding Author: Omar M.E. Abdel Salam, Department of Toxicology and Narcotics, National Research Centre, Tahrir St., Dokki, Cairo, Egypt, E-mail: omasalam@hotmail.com

Received: 18 Augus 2018; Accepted: 23 August 2018; Published: 27 August 2018

\begin{abstract}
Objective: Is to investigate the effect of Capsicum annuum L extract for its ability to prevent neuronal degeneration in rotenone intoxicated mice.
\end{abstract}

Methods: Rotenone $1.5 \mathrm{mg} / \mathrm{kg}$ was subcutaneously given three times per week for two consecutive weeks. Starting from the first day of rotenone treatment, mice also received intraperitoneal injections of Capsicum extract (56 or 224 $\mathrm{mg} / \mathrm{kg}$ ). The brain and liver content of the lipid peroxidation product malondialdehyde (MDA), nitric oxide, reduced glutathione (GSH), paraoxonase 1 activity as well as brain cholinesterase and 5-lipoxygenase activities were determined. Histopathology and glial fibrillary acidic protein (GFAP) immunostaining in brain were also performed.

Results: Rotenone treatment caused significantly raised brain and liver MDA by $64.4 \%$ and $93.3 \%$ and nitric oxide by $77.8 \%$ and $40.3 \%$, respectively. Reduced glutathione decreased by $45.4 \%$ and $24.3 \%$ and PON1 activity fell by $39.4 \%$ and $28.7 \%$ in both the brain and liver, respectively. Cholinesterase activity in brain was inhibited by $60.6 \%$ while 5-lipoxygenase increased by $38.9 \%$. In brain tissue, Capsicum prevented the increase in MDA and nitric oxide levels. Capsicum also restored GSH, PON-1 activity and alleviated the increase in 5-lipoxygenase activity. Cholinesterase activity was almost restored to control value by the higher dose of Capsicum. In the liver tissue, Capsicum caused a significant decrease in MDA, and nitric oxide levels, and increased GSH. It also increased PON- 
1 activity. The neurotoxicity of rotenone was prevented by the administration of Capsicum extract which prevented the neuronal degeneration and restored GFAP positive cells.

Conclusions: Capsicum exerts a neuroprotective effect in rotenone intoxicated mice and this is likely to involve reduced oxidative stress and 5-lipoxygenase activation.

Keywords: Capsicum annuum; Hot pepper; capsaicin; Rotenone; Parkinson's disease; Oxidative stress; 5lipoxygenase

\section{Introduction}

Parkinson's disease (PD) is a neurodegenerative disorder in which there is continued degeneration of the pigmented dopaminergic neurons of the substantia nigra pars compactica (SNPc) of the midbrain [1]. A substantial loss of these neurons (60\%-70\% in SNPc and 70\%-80\% in striatum) results in the disordered motor activity characteristic of the disease i.e., bradykinesia or akinesia, muscular rigidity, tremor, and postural instability [1-3]. Sporadic Parkinson's disease accounts for the majority of cases ( $>95 \%)$ and occurs in the old age ( $>65$ years) [4]. The exact cause leading to the death of the dopaminergic neurons in PD is not yet fully explained. It is likely that certain environmental toxins could trigger a cascade of oxidative or inflammatory events resulting in the neurodegeneration in those who bear genetic susceptibility [5,6]. Evidence for oxidative damage to cell membrane lipids, proteins and DNA, mitochondrial dysfunction and decreased mitochondrial complex I activity, and neuroinflammation is indicated by findings in postmortem brain of PD subjects and in toxin models of PD and suggests an important role for these pathogenic mechanisms in the degeneration of neurons [7-10].

Until nowadays, the treatment of PD subjects relies on providing dopamine to the brain to replace the biochemical deficit. This is achieved via administering the dopamine precursor levodopa (L-3,4-dihydroxyphenylalanine) or Ldopa along with a peripheral decarboxylase inhibitor to increase the availability of L-dopa to the brain. Other lines of treatment aiming at enhancing brain dopaminergic activity are the use of dopamine receptor agonist drugs, monoamine oxidase type B inhibitors and catechol-O-methyl transferase inhibitors to decrease L-dopa breakdown $[11,12]$. None of these drugs lessens disease progression and after several years, these treatments, however, became less effective owing to the continued loss of dopamine cells. Moreover, the emergence of L-dopa induced motor complications i.e., dyskinesia and motor fluctuations presents another therapeutic challenge [11, 13]. This illustrates the need for disease modifying or neuroprotective agents that would interfere with the ongoing neurodegenerative process.

In the search for new agents to halt or prevent neurodegeneration, botanicals represent important and promising candidates [14, 15]. Capsicum fruits (peppers) of the genus Solanaceae are widely consumed by humans as both vegetables and spices. Both sweet and hot peppers are included in the human diet; hot green or red peppers, are however, favored in many parts of the World such as Mexicao, India, and Thailand, because of their characteristic pungency and represent an important spice in the cuisines in these countries [16]. Peppers are also rich in 
carotenoids, flavonoids, phenolics, and ascorbate making these fruits important nutraceuticals $[17,18]$. Hot peppers, on the other hand, contain the vanilloid compound capsaicin (8-methyl-N-vanillyl-6-nonenamide), the ingredient accounting for their pungency and the perceived burning sensation [19, 20]. Capsaicin is a sensory stimulant and acts on the transient receptor potential vanilloid 1 (TRPV1), a nonselective cation channel in the plasma membrane [21]. Capsaicin exerts protective effects in the stomach [22, 23], liver [24], as well as in models of cerebral ischemia in gerbils [25] and 1-methyl-4-phenyl-1,2,3,6-tetrahydropyridine (MPTP) Parkinson's disease in mice [26].

In this study, we investigated the potential therapeutic and neuroprotective effects of Capsicum annuum L extract in the rotenone intoxicated mice. Rotenone, is a pesticide of plant origin that is widely used to induce PD in rodents, causing nigrostriatal cell death, and alpha-synuclein-positive cytoplasmic inclusions [27, 28]. Rotenone inhibits mitochondrial complex I activity [29], increases the generation of reactive oxygen metabolites and nitric oxide, NF$\kappa B$ [30-34] and increases tumor necrosis factor-alpha (TNF- $\alpha$ ), monocyte chemoattractant protein-1 (MCP-1) and interleukin-1beta (Il-1 $\beta$ ) in the rat brain [35-37]. Rotenone thus causes nigrostriatal cell death by inducing the development of both oxidative/nitrosative stress and neuroinflammation.

\section{Materials and methods}

\subsection{Animals}

Swiss male albino mice, weighing 25-26 g from the breeding colony at the National Research Center, Cairo, were used. Experiments were done according to the recommendations of the Ethics Committee of the Institution and followed that of the National Institutes of Health Guide for Care and Use of Laboratory Animals (Publication No. 85-23, Revised 1985).

\subsection{Drugs and chemicals}

Rotenone was obrained from Sigma-Aldrich (St Louis, MO, USA) and dissolved in $100 \%$ dimethyl sulfoxide. The Capsicum fruits were obtained from local market in Giza province (Figure 1). The Capsicum fruits (100 g) were crushed and extracted with $70 \%$ methanol by soaking at room temperature and the methanol extract was evaporated under reduced pressure and lyophilized.

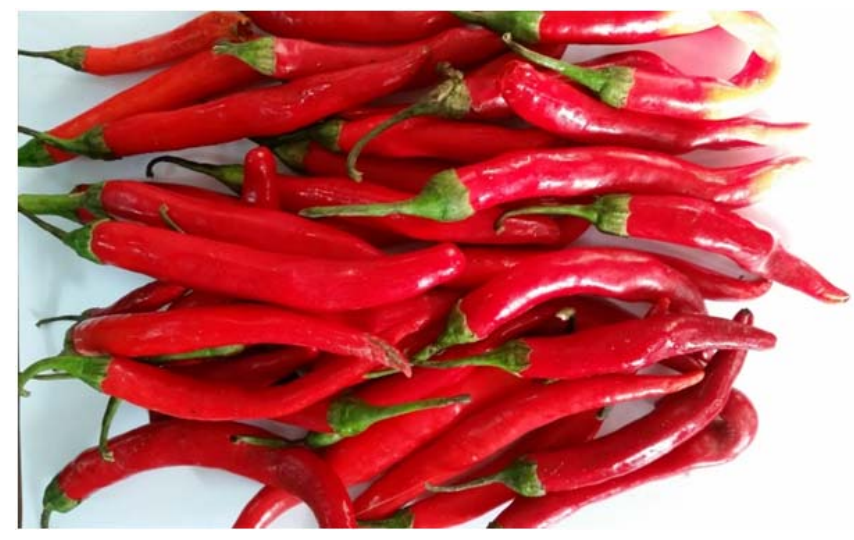

Figure 1: Capsicum annuum L. 


\subsection{Study design}

Mice were randomly divided into four equal groups, with six mice in each group. Group 1 received the vehicle while groups 2-4 were treated with rotenone $1.5 \mathrm{mg} / \mathrm{kg}$, subcutaneously, three times a week for two consecutive weeks. Beginning from the first day of rotenone injection, groups 3 and 4 were also given intraperitoneal injections of Capsicum extract at doses of 56 or $224 \mathrm{mg} / \mathrm{kg}$. Mice were euthanized by decapitation for tissue collection; their brain and liver were quickly removed out on an ice-cold plate, washed with ice-cold phosphate-buffered saline (pH 7.4), weighed, and stored at $-80^{\circ} \mathrm{C}$ for biochemical assays. Tissue homogenization was done with $0.1 \mathrm{M}$ phosphatebuffered saline $(\mathrm{pH} 7.4)$ to give a final concentration of $10 \%$ weight/volume.

\subsection{Biochemical analyses}

2.4.1. Determination of Lipid peroxidation: Malondialdehyde (MDA), an end product of lipid peroxidation was measured according to the method described by Nair and Turne [38]. In brief, thiobarbituric acid reactive substances (TBAS) react with thiobarbituric acid forming TBA-MDA adduct and the absorbance is read at $532 \mathrm{~nm}$ using spectrophotometer.

2.4.2. Determination of Nitric oxide: Nitric oxide was measured using Griess reagent according to Moshage et al. [39]. Nitrate is converted to nitrite by nitrate reductase. Griess reagent then converts nitrite to a deep purple azo compound. The absorbance is read at $540 \mathrm{~nm}$ using spectrophotometer.

2.4.3. Determination of Reduced glutathione: Reduced glutathione (GSH) was determined in homogenates according to Ellman et al. [40] where Ellman's reagent (5, 5\-dithiobis-2-nitrobenzoic acid) is reduced by sulfhydryl groups to form 2-nitro-5-mercaptobenzoic acid. The latter has an intense yellow color and is determined colorimetrically at $412 \mathrm{~nm}$.

2.4.4. Determination of Paraoxonase- 1 activity: Paraoxonase-1 arylesterase activity was determined using phenylacetate as a substrate and the formation of phenol was measured by monitoring the increase in absorbance at $270 \mathrm{~nm}$ and $25^{\circ} \mathrm{C}$ with a spectrophotometer. One unit of arylesterase activity is defined as $1 \mu \mathrm{M}$ of phenol produced per minute. Enzyme activity is calculated based on the extinction coefficient of phenol $\left(1310 \mathrm{M}^{-1} \mathrm{~cm}^{-1}\right.$ at $270 \mathrm{~nm}$, $\mathrm{pH} 8.0$ and $\left.25^{\circ} \mathrm{C}\right)$ and expressed as kilo International Units/Liter (kU/L) [41].

2.4.5. Determination of Cholinesterase activity: Butyrylcholinesterase (BChE) activity was measured with a commercially available kit (Ben Biochemical Enterprise, Milan, Italy). BChE catalyzes the hydrolysis of butyrylthiocholine as a substrate into butyrate and thiocholine. The latter reacts with 5, 5'-dithiobis (2-nitrobenzoic acid) (DTNB) to produced a yellow chromophore which then could be quantified using spectrophotometer [42].

2.4.6. Determination of 5-lipoxygenase: 5-lipoxygenase was determined using a double-antibody sandwich enzyme-linked immunosorbent assay (Rat (5-LO/LOX) ELISA kit) from Shanghai Sunred Biological Technology Co., Ltd, Jufengyuan Road, Baoshan District, Shanghai. 


\subsection{Histopathological studies}

Brains of all animals were dissected immediately after death. The specimens were then fixed in $10 \%$ neutralbuffered formalin saline for at least 72 hours. Specimens were then washed in tap water for half an hour, dehydrated in ascending grades of alcohol, cleared in xylene and finally embedded in paraffin. Serial sections of $6 \mu \mathrm{m}$ thick were cut and stained with haematoxylin and eosin for histopathological investigations.

\subsection{GFAP Immunohistochemistry}

Immunohistochemistry for glial fibrillary acidic protein (GFAP) were performed on paraffin-embedded brain sections that were were deparaffinized and rehydrated. Immunohistochemistry was performed with mouse monoclonal antibodies against glial fibrillary acidic protein (GFAP) for detection of the GFAP activity. In brief, the paraffin sections were heated in a microwave oven $(25 \mathrm{~min}$ at $720 \mathrm{~W})$ for antigen retrieval and incubated with antiGFAP antibodies (1:50 dilution) overnight at $4^{\circ} \mathrm{C}$. After washing with PBS, followed by incubation with biotinylated goat-anti-rabbit immunoglobulin G secondary antibodies (1:200 dilution; Dako Corp, Carpinteria, CA, USA) and streptavidin/alkaline phosphatase complex (1:200 dilution; Dako) for 30 min at room temperature, the binding sites of antibody were visualized with 3,3'-diaminobenzidine DAB (Sigma-Aldrich). After washing with PBS, the samples were counterstained with H\&E for 2-3 min, and dehydrated by transferring them through increasing ethanol solutions $(30 \%, 50 \%, 70 \%, 80 \%, 95 \%$, and 100\% ethanol). Following dehydration, the slices were soaked twice in xylene at room temperature for $5 \mathrm{~min}$, mounted, examined, and evaluated by a high power light microscope.

\subsection{GFAP Immunomorphometric quantification}

Further histopathological evaluation, quantitative morphometric analysis of GFAP immunostaining was done. An image processing and analysis system (A Leica QWin Cambridge, UK) was used for interactive automatic measurement of the areas percentage carried out on slides stained with GFAP by analyzing ten random fields per slide.

\subsection{Statistical analysis}

Data are presented as mean \pm SE. The data are analyzed using one way analysis of variance, followed by Duncan's multiple range test for post hoc comparison of group means. Results with a probability of $\mathrm{p}<0.05$ are considered statistically significant.

\section{Results}

\subsection{Biochemical results}

3.1.1. Lipid peroxidation: Compared to the vehicle-treated group, mice treated with only rotenone exhibited significantly increased brain and liver malondialdehyde (MDA) levels by $64.4 \%$ and 93.3\%, respectively. Capsicum given at 56 or $224 \mathrm{mg} / \mathrm{kg}$ resulted in significant decrease in brain MDA by $47.8 \%$ and 39.4\%, respectively, compared to the rotenone control group (Table 1). Capsicum at $56 \mathrm{mg} / \mathrm{kg}$ had no significant effect on liver MDA. 
The higher dose of the extract, however, resulted in $24.1 \%$ decrease in liver MDA, compared to the rotenone control value (Table 2).

\begin{tabular}{|c|c|c|c|c|}
\hline Compound & $\begin{array}{l}\text { Malondialdehyde } \\
\text { (nmol/g.tissue) }\end{array}$ & $\begin{array}{l}\text { Nitric oxide } \\
(\mu \mathrm{mol} / g . t i s s u e)\end{array}$ & $\begin{array}{l}\text { Reduced } \\
\text { glutathione } \\
\text { ( } \mu \mathrm{mol} / \text { g.tissue) }\end{array}$ & $\begin{array}{l}\text { PON-1 activity } \\
\text { (kU/l) }\end{array}$ \\
\hline Vehicle & $24.7 \pm 1.5$ & $19.4 \pm 0.7$ & $3.3 \pm 0.12$ & $19.3 \pm 1.4$ \\
\hline Rotenone & $40.6 \pm 2.5^{*}$ & $34.5 \pm 1.2^{*}$ & $1.8 \pm 0.05^{*}$ & $11.7 \pm 0.9^{*}$ \\
\hline $\begin{array}{l}\text { Rotenone }+ \text { Capsicum } \\
\text { extract } 56 \mathrm{mg} / \mathrm{kg}\end{array}$ & $\begin{array}{l}21.2 \pm 1.3^{+} \\
(-47.8 \%)\end{array}$ & $\begin{array}{l}16.0 \pm 0.7^{+\#} \\
(-53.6 \%)\end{array}$ & $\begin{array}{l}3.2 \pm 0.18^{+\#} \\
(77.8 \%)\end{array}$ & $\begin{array}{l}29.1 \pm 1.6^{+\#} \\
(148.7 \%)\end{array}$ \\
\hline $\begin{array}{l}\text { Rotenone }+ \text { Capsicum } \\
\text { extract } 224 \mathrm{mg} / \mathrm{kg}\end{array}$ & $\begin{array}{l}24.6 \pm 0.9^{+} \\
(-39.4 \%)\end{array}$ & $\begin{array}{l}13.8 \pm 0.5^{+\#} \\
(-60.0 \%)\end{array}$ & $\begin{array}{l}3.7 \pm 0.11^{+\#} \\
(105.5 \%)\end{array}$ & $\begin{array}{l}28.0 \pm 1.2^{+\#} \\
(139.3 \%)\end{array}$ \\
\hline
\end{tabular}

Results are means \pm SEM. Statistical analysis was done using one-way ANOVA and Duncan multiple range test.*p $<$ 0.05 vs. vehicle. $+\mathrm{p}<0.05$ vs. rotenone control. The percent change from the rotenone only group is shown in parenthesis.

Table 1: The effect of Capsicum extract on malondialdehyde, nitric oxide, reduced glutathione and paraoxonase-1 activity in the brain of rotenone-treated mice.

\begin{tabular}{|c|c|c|c|c|}
\hline Compound & $\begin{array}{l}\text { Malondialdehyde } \\
\text { (nmol/g.tissue) }\end{array}$ & $\begin{array}{l}\text { Nitric oxide } \\
\text { ( } \mu \mathrm{mol} / \text { g.tissue) }\end{array}$ & $\begin{array}{l}\text { Reduced glutathione } \\
\text { ( } \mu \mathrm{mol} / \text { g.tissue) }\end{array}$ & $\begin{array}{l}\text { PON-1 activity } \\
\text { (kU/l) }\end{array}$ \\
\hline Vehicle & $31.5 \pm 2.1$ & $40.2 \pm 1.6$ & $7.0 \pm 0.5$ & $38.0 \pm 2.1$ \\
\hline Rotenone & $60.9 \pm 3.4^{*}$ & $56.4 \pm 3.8^{*}$ & $5.3 \pm 0.2^{*}$ & $27.1 \pm 1.4^{*}$ \\
\hline $\begin{array}{l}\text { Rotenone } \\
\text { Capsicum extract } 56 \\
\mathrm{mg} / \mathrm{kg}\end{array}$ & $55.3 \pm 3.7^{*}$ & $\begin{array}{l}46.5 \pm 1.9^{+} \\
(-17.5 \%)\end{array}$ & $\begin{array}{l}6.1 \pm 0.1^{+} \\
(15.1 \%)\end{array}$ & $\begin{array}{l}30.6 \pm 2.0^{*} \\
(12.9 \%)\end{array}$ \\
\hline $\begin{array}{l}\text { Rotenone } \\
\text { Capsicum extract } \\
224 \mathrm{mg} / \mathrm{kg}\end{array}$ & $\begin{array}{l}46.2 \pm 1.8^{+\#} \\
(-24.1 \%)\end{array}$ & $\begin{array}{l}41.9 \pm 2.5^{+} \\
(-25.7 \%)\end{array}$ & $\begin{array}{l}6.2 \pm 0.2^{+} \\
(17.0 \%)\end{array}$ & $\begin{array}{l}38.3 \pm 1.5^{+} \\
(41.3 \%)\end{array}$ \\
\hline
\end{tabular}

Results are means \pm SEM. Statistical analysis was done using one-way ANOVA and Duncan multiple range test.*p $<$ 0.05 vs. vehicle. $+\mathrm{p}<0.05$ vs. rotenone control. \# vs. Capsicum extract at $56 \mathrm{mg} / \mathrm{kg}$. The percent change from the rotenone only group is shown in parenthesis.

Table 2: The effect of Capsicum extract on malondialdehyde, nitric oxide, reduced glutathione and paraoxonase-1 activity in the liver of mice treated with rotenone. 
3.1.2. Nitric oxide: Nitric oxide in brain and liver of mice treated with rotenone exhibited significantly increased levels by $77.8 \%$ and $40.3 \%$ as compared to the vehicle-treated group. Following treatment with Capsicum extract at 56 or $224 \mathrm{mg} / \mathrm{kg}$, nitric oxide decreased significantly by 53.6-39.4\% and by $17.5-25.7 \%$ in both the brain and liver tissue respectively (Table 1 and Table 2).

3.1.3.Reduced glutathione: Rotenone only treated mice exhibited significant decrease in brain and liver tissue levels of reduced glutathione $45.4 \%$ and $24.3 \%$ of their corresponding vehicle control values, respectively. Capsicum extract given at 56 or $224 \mathrm{mg} / \mathrm{kg}$ resulted in significant increments in brain reduced glutathione by $77.8 \%$ and $105.5 \%$, respectively (Table 1 ). There was also significantly increased reduced glutathione levels by $15.1 \%$ and $17 \%$ in rotenone-treated mice given 56 or $224 \mathrm{mg} / \mathrm{kg}$ of Capsicum extract, as compared to the rotenone control value (Table 2).

3.1.4. Paraoxonase 1 activity: Rotenone-treated mice showed $39.4 \%$ and $28.7 \%$ decrease in PON-1 activity in both brain and liver tissue, respectively, compared with their vehicle control values. Brain PON-1 activity increased by 148.7\% and 139.3\%, following treatment with Capsicum extract at 56 or $224 \mathrm{mg} / \mathrm{kg}$, respectively (Table 1). There was also significant increase in liver PON-1 activity by $41.3 \%$ in mice treated with $224 \mathrm{mg} / \mathrm{kg}$ of Capsicum extract, as compared to the rotenone control value (Table 2).

3.1.5. 5-lipoxygenase: Rotenone caused significant increase in brain 5-lipoxygenase by $38.9 \%$, compared to the vehicle-treated group. A significant decrease in 5-lipoxygenase in brain of rotenone-treated mice by $19.6 \%$ and $33.8 \%$ was observed after treatment with Capsicum extract at 56 or $224 \mathrm{mg} / \mathrm{kg}$, respectively (Table 3).

3.1.6. Cholinesterase activity: In rotenone-treated mice, brain BChE activity showed significant inhibition by $60.6 \%$, compared to the vehicle control value. A significant increase in BChE activity by $29.2 \%$ and $139.3 \%$ was observed in mice given Capsicum extract at 56 or $224 \mathrm{mg} / \mathrm{kg}$, respectively, compared with the rotenone only treatment group (Table 4).

\begin{tabular}{|l|l|}
\hline Compound & 5-Lipoxygenase (ng/ml) \\
\hline Vehicle & $70.7 \pm 2.9$ \\
\hline Rotenone & $98.2 \pm 6.7^{*}$ \\
\hline Rotenone + Capsicum extract $56 \mathrm{mg} / \mathrm{kg}$ & $78.9 \pm 3.1^{+}(-19.6 \%)$ \\
\hline Rotenone + Capsicum extract $224 \mathrm{mg} / \mathrm{kg}$ & $65.0 \pm 4.2^{+\#}(-33.8 \%)$ \\
\hline
\end{tabular}

Results are means \pm SEM. Statistical analysis was done using one-way ANOVA and Duncan multiple range test. ${ }^{*} p<$ 0.05 vs. vehicle. $+\mathrm{p}<0.05$ vs. rotenone control. \# vs. Capsicum extract at $56 \mathrm{mg} / \mathrm{kg}$. The percent change from the rotenone only group is shown in parenthesis.

Table 3: The effect of Capsicum extract on brain 5-lipoxygenase in rotenone-treated mice. 


\begin{tabular}{|l|l|}
\hline Compound & BChE activity (U/l) \\
\hline Vehicle & $172.9 \pm 6.5$ \\
\hline Rotenone & $68.1 \pm 3.7^{*}$ \\
\hline Rotenone + Capsicum extract $56 \mathrm{mg} / \mathrm{kg}$ & $88.0 \pm 4.6^{*+}(29.2 \%)$ \\
\hline Rotenone + Capsicum extract $224 \mathrm{mg} / \mathrm{kg}$ & $162.3 \pm 7.5^{+\#}(138.3 \%)$ \\
\hline
\end{tabular}

Results are means \pm SEM. Statistical analysis was done using one-way ANOVA and Duncan multiple range test. ${ }^{*} p<$ 0.05 vs. vehicle. $+\mathrm{p}<0.05$ vs. rotenone control. \# vs. Capsicum extract at $56 \mathrm{mg} / \mathrm{kg}$. The percent change from the rotenone only group is shown in parenthesis.

Table 4: The effect of Capsicum extract on brain butyrylcholinesterase (BChE) activity in rotenone-treated rats.

\subsection{Histopathological results}

3.2.1. Substantia Nigra: Sections from the vehicle-treated group showed normal substantia nigra neurons with normal nucleiand granular basophilic cytoplasm (Figure 2A). The substantia nigra of rotenone- treated mice showed marked neuronal degeneration. Neurons were reduced in number and stained darkly (Figure 2B). Sections from the rotenone-treated mice given Capsicum extract at $56 \mathrm{mg} / \mathrm{kg}$ were associated with a lesser degree of neuronal degeneration, with few cells having pyknotic nuclei (Figure 2C). Rotenone-treated mice given Capsicum extract at $224 \mathrm{mg} / \mathrm{kg}$ showed normal substantia nigra cells in relation to their number and structure (Figure 2D).

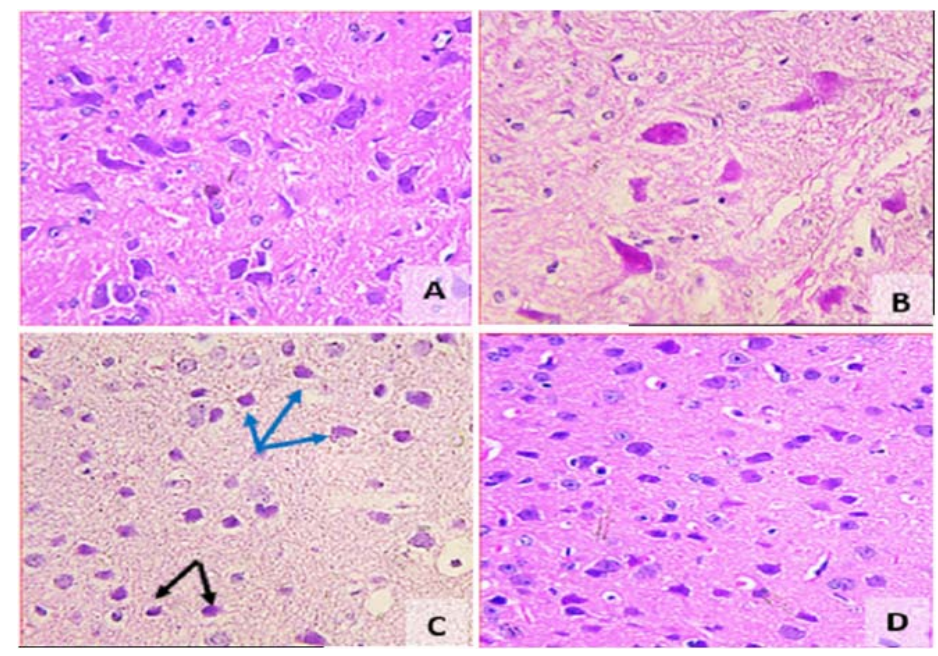

Figure 2: A representative photomicrograph of the substantia nigra for all tested groups: (A) Vehicle; (B) Rotonone only; (C) Rotenone + Capsicum extract $56 \mathrm{mg} / \mathrm{kg}$; (D) Rotenone + Capsicum extract $224 \mathrm{mg} / \mathrm{kg}$. Green arrows: normal neuronal cells. Black arrows: pyknotic cells. Blue arrows: degenerated neurons (H\&E 200x \&400x). 
3.2.2. Cerebral cortex: Hematoxylin and eosin-stained section from the vehicle-treated group showed a normal appearance with neurons having either single or double open-face nuclei with prominent nucleoli surrounded with basophilic cytoplasm. Astrocytes having sharply demarcated nuclei were seen (Figure 3A). Sections from rotenonetreated mice revealed degenerated neurons that appeared shrunken with dark basophilic cytoplasm and pyknotic nuclei. Other neurons showed neurocytic chromatolysis with vacuolated neutrophils and congested blood vessels (Figure 3B). Sections from rotenone-treated rats given Capsicum extract at $56 \mathrm{mg} / \mathrm{kg}$ contained almost normally appearing neuronal cells, except for pyknosis in some neurons (Figure 3C). The group treated with Capsicum extract at $224 \mathrm{mg} / \mathrm{kg}$ showed much better improvement (Figure 3D).
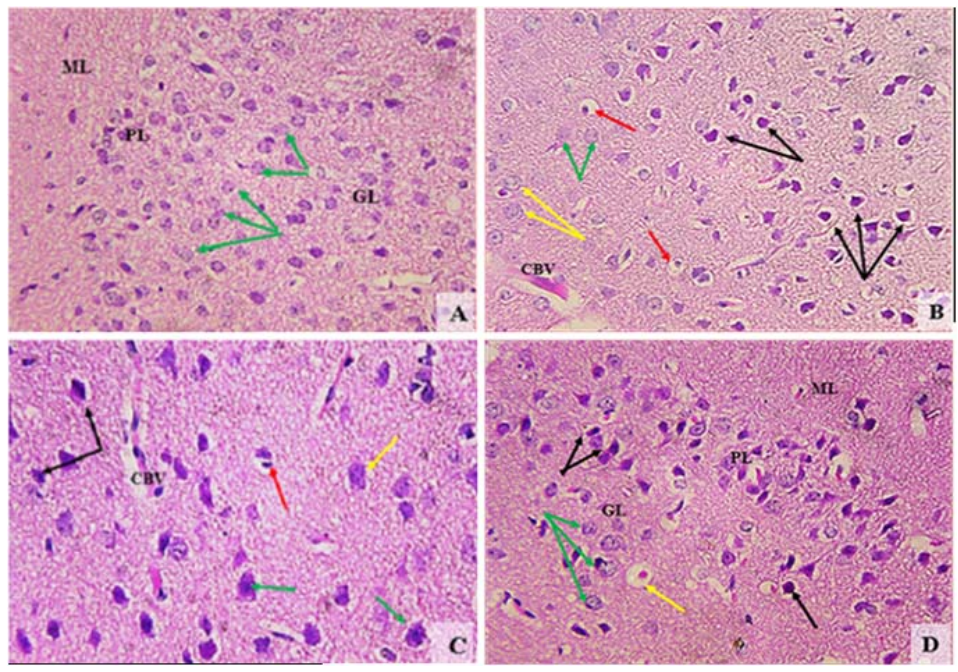

Figure 3: A representative photomicrograph of the cerebral cortex for all tested groups: (A) Vehicle; (B) Rotonone only; (C) Rotenone + Capsicum extract $56 \mathrm{mg} / \mathrm{kg}$; (D) Rotenone + Capsicum extract $224 \mathrm{mg} / \mathrm{kg}$. Green arrows: normal neuronal cells. Black arrows: pyknotic neurons. Yellow arrows: neurocyte chromatolysis. Red arrows: vacuolated neutrophils. CBV: congested blood vessel. ML: molecular layer. PL: pyramidal layer. GL: granular layer (H\&E 200x).

3.2.3. Hippocampus: The vehicle-treated group showed normal cellular composition in all layers (molecular, Purkinje, and granular (Figure 4A). Following rotenone injection, the hippocampus showed neuronal cell loss with mild degeneration when compared with controls. Neuronal cells with dense basophilic pyknotic nuclei were also seen (Figure 4B). A decrease in degenerated neurons was seen in sections from rotenone-treated rats given Capsicum extract at $56 \mathrm{mg} / \mathrm{kg}$ (Figure 4C). The rotenone-treated group given Capsicum at $224 \mathrm{mg} / \mathrm{kg}$ showed normal hisopathological picture when compared with control one (Figure 4D). 


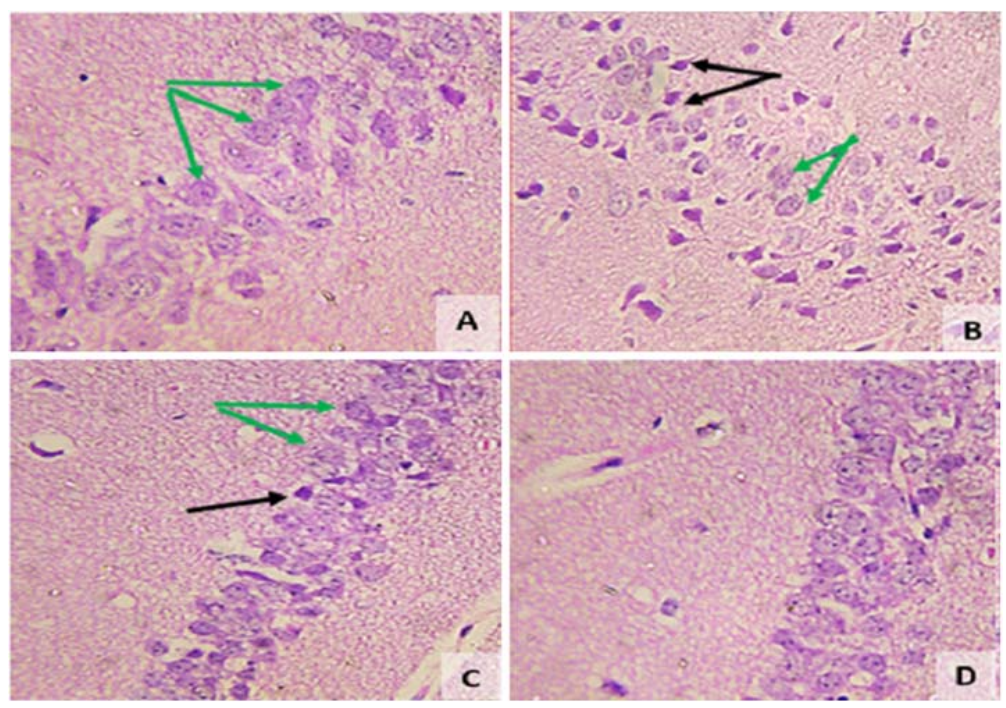

Figure 4: A representative photomicrograph of the hippocampus for all tested groups: (A) Vehicle; (B) Rotonone only; (C) Rotenone + Capsicum extract $56 \mathrm{mg} / \mathrm{kg}$; (D) Rotenone + Capsicum extract $224 \mathrm{mg} / \mathrm{kg}$. Green arrows: normal neuronal cells. Black arrows: pyknotic cells (H\&E 200x \& 400x).

\subsection{GFAP immunohistochemistry}

Sections stained with GFAP antibody from the vehicle group showed the normal appearance of glial cells in cerebral cortex; cells appeared star shaped with the thin fibers having regular course (Figure 5A). Rotenone caused marked decrease in GFAP positive cells (Figure 5B). This effect of rotenone decreased by treatment with Capsicum extract in a dose-dependent manner (Figure 5C and 5D). Quantitative assessment of the area of viable cells was calculated by image analyzer system (Figure 6) and indicated a significant decrease in the rotenone-treated groups than in the control group. Treatment with Capsicum in different doses resulted in a significant improvement when compared with rotenone only group (Table 5).

\begin{tabular}{|l|l|}
\hline Compound & GFAP Area (\%) \\
\hline Vehicle & $31.36 \pm 1.22$ \\
\hline Rotenone & $4.69 \pm 0.61^{{ }^{*}}$ \\
\hline Rotenone + Capsicum extract $56 \mathrm{mg} / \mathrm{kg}$ & $15.21 \pm 1.19^{{ }^{*}}(224.3 \%)$ \\
\hline Rotenone + Capsicum extract $224 \mathrm{mg} / \mathrm{kg}$ & $17.25 \pm 1.40^{{ }^{+}}(267.8 \%)$ \\
\hline
\end{tabular}

Results are means \pm SEM. Statistical analysis was done using one-way ANOVA and Duncan multiple range test. ${ }^{*} \mathrm{p}<$ 0.05 vs. vehicle. $+p<0.05$ vs. rotenone control. The percent change from the rotenone only group is shown in parenthesis.

Table 5: Immunomorphometric measurments of GFAP. 


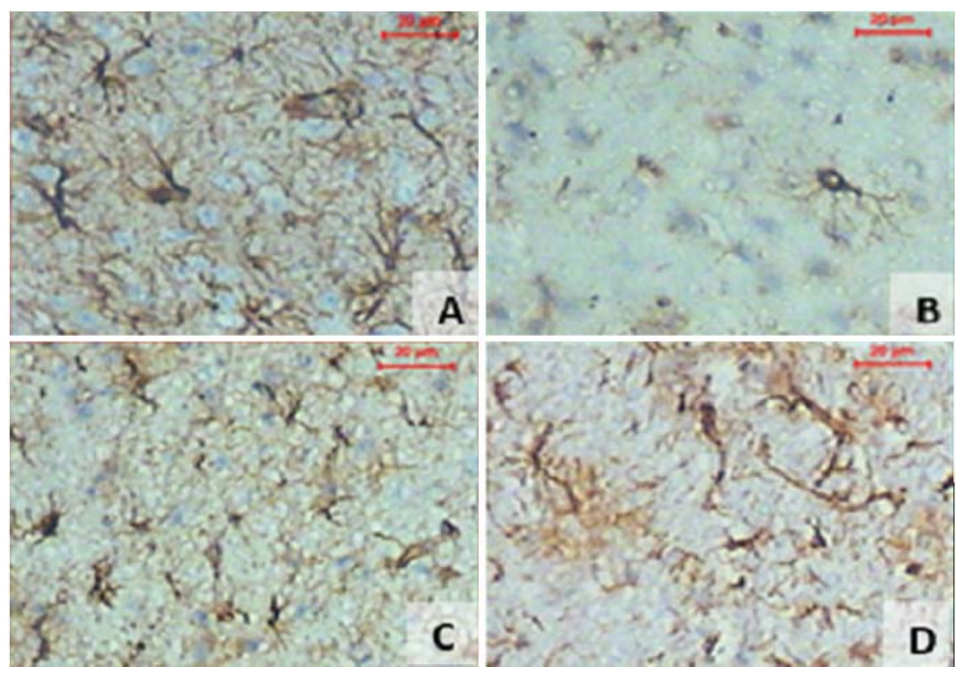

Figure 5: A representative photomicrograph of the cerebral cortex for all tested groups showing immunoreactivity of glial fibrillary acidic protein (GFAP): (A) Vehicle; (B) Rotonone only; (C) Rotenone + Capsicum extract 56 $\mathrm{mg} / \mathrm{kg}$; (D) Rotenone + Capsicum extract $224 \mathrm{mg} / \mathrm{kg}$. (GFAP 200x) .

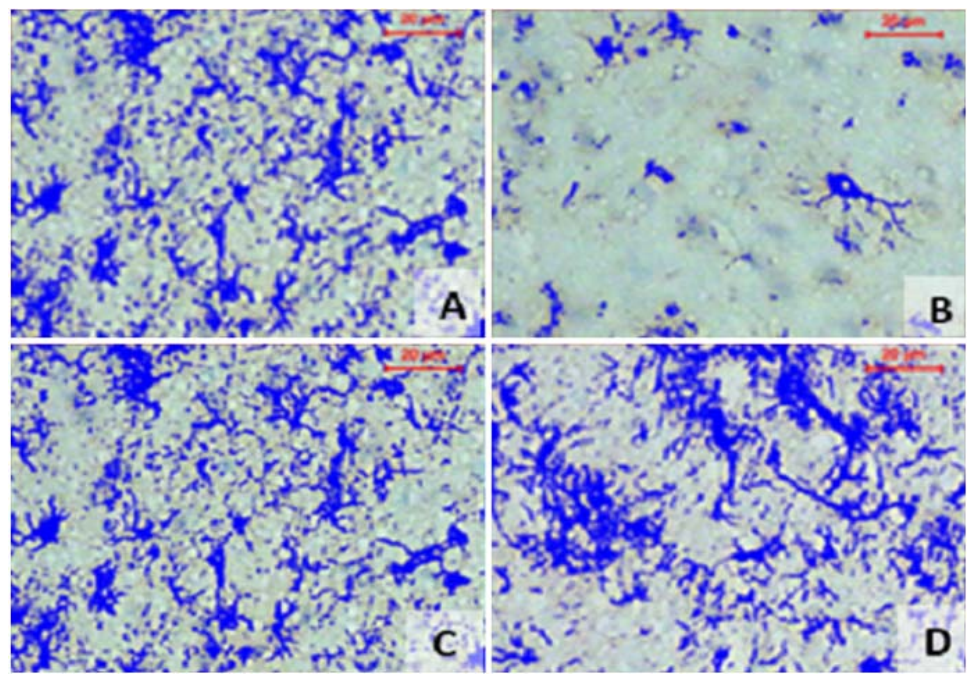

Figure 6: Captured photos from the image analyser system marking the immunoreactivity of brain tissues to GFAP by blue color : (A) Vehicle; (B) Rotonone only; (C) Rotenone + Capsicum extract $56 \mathrm{mg} / \mathrm{kg}$; (D) Rotenone + Capsicum extract $224 \mathrm{mg} / \mathrm{kg}$ (GFAP 200x).

\section{Discussion}

In this study, Capsicum annuum extract was investigated for its ability to prevent neuronal degeneration in rotenone intoxicated rats. We found that the administration of Capsicum extract protected against neuronal cell injury caused by rotenone. The administration of rotenone caused brain oxidative stress which is in accordance with other published studies [30-37]. There was increased level of the lipid peroxidation end product malondialdehyde, suggesting an attack on membrane lipids by intracellular reactive oxygen metabolites [43]. Meanwhile, the level of Journal of Pharmacy and Pharmacology Research Vol. 2 No. 3 - Sep 2018. 
reduced glutathione, an antioxidant and a free radical scavenger [44] decreased significantly, possibly due to its consumption by the increased free radicals. Rotenone has been shown to increase the release of reactive oxygen species in vitro [45], increase lipid peroxidation products and to decrease GSH and catalase activity in rodent brain $[33,34,46]$.The increased generation of reactive oxygen metabolites and the ensuing oxidative stress is considered an important pathogenic mechanism that underlies the rotenone-induced cell death [29-31]. In this context, the rotenone-induced decrease in TH-ir in substantia nigra cells could be rescued by the antioxidant $\alpha$-tocopherol [31]. Moreover, vitamin $\mathrm{C}$ given along with indomethacin or nimesulide to rotenone treated mice alleviated the biochemical, and motor changes and neuronal damage caused by rotenone in mice [47]. In this study, Capsicum exerted an antioxidative action, reversing the changes in brain levels of lipid peroxidation and reduced glutathione; these effects might have been contributed to the observed neuroprotection.

Increased generation of nitric oxide is also an important contributor to the mechanisms by which rotenone caused neuronal damage [32, 48, 49]. Rotenone increases the expression of the inducible form of nitric oxide synthase (iNOS) in the striatum and substantia nigra and increases the level of nitric oxide brain of rodents [35, 36]. Increased generation of nitric oxide via neuronal NOS could also be involved in the rotenone neurotoxicity. This is the increase in NOS activity and 3-nitrotyrosine and nigrostriatal damage in rats treated with rotenone was reduced by the administration of the neuronal NOS inhibitor 7-nitroindazole [49]. Moreover, iNOS gene deletion or inhibition of nNOS conferred resistance against nigrastriatal toxicity cause by 1-methyl-4-phenyl-1,2,3,6-tetrahydropyridine (MPTP) in mice [48]. There is compelling evidence that the increase in nitric acid formation for prolonged time such as that occurring in inflammatory or toxic conditions is cause of neuronal death. The reaction of nitric oxide with molecular oxygen yielding reactive oxides of nitrogen eg., nitrogen dioxide $\left(\mathrm{NO}_{2}\right)$, dinitrogen trioxide $\left(\mathrm{N}_{2} \mathrm{O}_{3}\right)$, with the superoxide anion $\left(\mathrm{O}_{2}{ }^{-}\right)$causing the formation of reactive peroxynitrite, leads to oxidation, nitrosylation of thiols in proteins or reduced glutathione, and nitration of tyrosine residues in proteins [50, 51]. Oxidative/nitrosative stress and inactivation of several mitochondrial electron transport complexes including complex I, causing mitochondrial dysfunction, inhibition of mitochondrial respiration and depletion of cellular energy ensue leading finally to neuronal cell death [52]. In this study, rotenone resulted in marked increase in brain nitric oxide which could be prevented by Capsicum extract.

The lipid mediators Leukotrienes (LTs) are produced from arachidonic acid via the 5-lipoxygenase pathway. These are LTB(4) and cysteinyl leukotrienes (CysLTs) and which play an important role in brain inflammation [53,54]. In this study, the level of 5-lipoxygenase in brain increased after rotenone treatment. Other studies reported upregulation of 5-lipoxygenase expression in microglia and increased release of IL-1 $\beta$ and TNF- $\alpha$ by rotenone which could be prevented by selective receptor antagonists of LTB(4) and CysLTs [55]. The latter were also shown to decrease dopamine cell injury following rotenone application in vitro [56]. In rats, montelukast, a CysLTs receptor antagonist was shown to exert an antioxidant effects and to ameliorate the rotenone-induced neurodegenerative changes [46]. 
Our results also indicate marked inhibition of PON-1 activity following rotenone injection which is in agreement with previous observations [33-37]. The enzyme PON-1 which is synthesized by the liver and circulates bound to low density plasma proteins [57] is endued with important antioxidative and anti-inflammatory roles [58] and a decrease in its activity has been shown in a number of neurologic disorders [59]. The inhibition in PON-1 activity by rotenone has been shown in several studies and could have resulted from a direct toxic action of rotenone or by an increase in oxidative stress which has been shown to inactivate the enzyme [60]. In the present study, treatment capsicum extract was found to result in marked increase in PON-1 activity in brain of rotenone intoxicated mice which could be due to the decrease in the level of oxidative stress or a consequence to neuroprotection.

In this study, the administration of rotenone caused a significant inhibition of brain cholinesterase activity, a finding which agrees with our previous studies. Rotenone not only damage dopaminergic neurons, but also serotonergic and cholinergic neurons are affected by the toxicant [61]. Hence, the decrease in cholinesterase activity after rotenone could be due to the loss of cholinergic neurons. It is also possible that the observed decline in enzyme activity is a result of direct inhibitory action of rotenone. Nevertheless, the restoration of cholinesterase activity by Capsicum extract is indicative of a neuroprotective action.

The ability of capsicum extract to protect against the rotenone neurotoxicity was confirmed by histopathological examination and by measurement of GFAP immunoreactivity. Rotenone caused a decrease pigmented neurons in the substantia nigra and neuronal degeneration in the cerebral cortex and hippocampus. There was also significantly decreased glial fibrillary acidic protein (GFAP)-positive astrocytes in the cerebral cortex which is in accordance with previous observations [34]. Our results indicate a decrease in the extent of neuronal degeneration in the substantia nigra, cerebral cortex and hippocampus by Capsicum at $56 \mathrm{mg} / \mathrm{kg}$, while treatment with the higher dose of the extract resulted in almost normalization of the histologic picture. Capsicum also rescued GFAP-positive astrocytes.

When injected into rats, rotenone has been shown to cause vacuolar degeneration [37] and fatty changes [62]. In this study, the effect of rotenone on the liver was also investigated. Rotenone caused a significant increase in malondialdehyde and nitric oxide contents in liver tissue. The level of reduced glutathione and the activity of PON-1 decreased. Our findings suggest that oxidative stress occurs in the liver after rotenone injection and that oxidative damage to liver tissue account for the reported pathological changes in the liver of rotenone-treated rats. The study also showed a decrease in oxidative stress following treatment with Capsicum extract, suggesting a protective effect.

The exact constituent(s) that account for the observed protective effects of Capsicum is difficult to ascertain. Peppers are known for their rich content of carotenoids, flavonoids, phenolics, and vitamin C $[17,18]$ and these are well known to exert neuroprotective effects $[63,64]$. Capsicum fruits of the hot varities are also characterized by the presence of their active pungent principle capsaicin. The latter is a sensory stimulant and in low concentrations selectively stimulates a subset of primary afferent neurons with unmyelinated $\mathrm{C}$ fiber or thin myelinated A $\delta$ fibers. Most of these fibers are polymodal nociceptors [20]. The molecular site of action of capsaicin is the transient 
receptor potential vanilloid 1 (TRPV1), a nonselective cation channel in the plasma membrane [21]. Capsaicin excites the peripheral nerve ending of capsaicin-responsive sensory neurons, releasing their content of neuropeptides eg., substance P, and calcitonin gene related peptide [20]. The latter has been shown to account for the increase in blood flow and the protective effects of capsaicin in the stomach [65]. Capsaicin has also been reported to decrease neuronal damage in experimental models of cerebral ischemia [25] and MPTP-induced Parkinson's disease [26].

In summary, the findings in the present study indicate a protective action for Capsicum extract against the rotenone neurotoxicity. Capsicum exerted an antioxidative action, decreasing brain lipid peroxidation and increasing reduced glutathione content as well as lessening the increase in brain 5-lipoxygenase induced by rotenone. Our data therefore suggest that an antioxidant action and a decrease in the inflammatory response are both likely to have been contributed to the observed neuroprotection.

\section{Conflicts of Interest Statement}

The authors declare that there are no potential conflicts of interest.

\section{Acknowledgement}

This work was not supported by research grants.

\section{References}

1. Hughes AJ, Daniel SE, Kilford L, et al. Accuracy of clinical diagnosis of idiopathic Parkinson's disease: a clinico-pathological study of 100 cases. J Neurol Neurosurg Psychiatry 55 (1992): 181-184.

2. Lehosit JB, Cloud LJ. Early parkinsonism: distinguishing idiopathic Parkinson's disease from other syndromes. JCOM 22 (2015): 257-265.

3. Magrinelli F, Picelli A, Tocco P, et al. Pathophysiology of motor dysfunction in Parkinson's disease as the rationale for drug treatment and rehabilitation. Park Dis (2016): 9832839.

4. Wirdefeldt K, Adami HO, Cole P, et al. Epidemiology and etiology of Parkinson's disease: a review of the evidence. Eur J Epidemiol 26 (2011): S1-58.

5. Ritz BR, Paul KC, Bronstein JM. Of pesticides and men: a California story of genes and environment in Parkinson's disease. Curr Environ Health Rep 3 (2016): 40-52.

6. Jiang T, Sun Q, Chen S. Oxidative stress: A major pathogenesis and potential therapeutic target of antioxidative agents in Parkinson's disease and Alzheimer's disease. Prog Neurobiol 147 (2016): 1-19.

7. Nagatsu T, Sawada M. Biochemistry of postmortem brains in Parkinson's disease: historical overview and future prospects. J Neural Transm Suppl 72 (2007): 113-120.

8. Blesa J, Trigo-Damas I, Quiroga-Varela A, et al. Oxidative stress and Parkinson's disease. Front Neuroanat 9 (2015): 91.

9. De Virgilio A, Greco A, Fabbrini G, et al. Parkinson's disease: autoimmunity and neuroinflammation. Autoimmun Rev 15 (2016): 1005-1011.

10. Hu Q, Wang G. Mitochondrial dysfunction in Parkinson's disease. Transl Neurodegener 5 (2016): 14. 
11. Abdel-Salam OME. Drug therapy for Parkinson's disease: an update. World J Pharmacol 4 (2015): 117143.

12. Kalia LV, Lang AE. Parkinson's disease. Lancet 386 (2015): 896-912.

13. Maiti P, Manna J, Dunbar GL. Current understanding of the molecular mechanisms in Parkinson's disease: Targets for potential treatments. Transl Neurodegener 6 (2017): 28.

14. Abdel-Salam OME, Gaafar A E-DM. Dietary Antioxidants in Parkinson's Disease. In: Food and Parkinson's Disease. Essa MM, Manivasagam T, Justin A Thenmozhi, Khan MAS (Eds). Nova Science Publishers ISBN: 978-1-63485-754-3. Chapter 2 (2016): 15-40.

15. Dey A, De J.N. Neuroprotective therapeutics from botanicals and phytochemicals against Huntington's disease and related neurodegenerative disorders. Journal of Herbal Medicine 5 (2015): 1-19.

16. Crosby KM. Pepper. In: Prohens J, Nuez F. Vegetables II. Handbook of Plant Breeding, Springer, New York, NY 2 (2008): 221-248.

17. Arimboor R, Natarajan RB, Menon KR, Chandrasekhar LP, et al. Red pepper (Capsicum annuum) carotenoids as a source of natural food colors: analysis and stability-a review. J Food Sci Technol 52 (2015): 1258-1271.

18. Jayaprakasha GK, Bae H, Crosby K, et al. Bioactive compounds in peppers and their antioxidant potential. In: Hispanic Foods: Chemistry and Bioactive Compounds 4 (2012): 43-56.

19. Abdel-Salam OME. Preference for hot pepper: A complex interplay of personal, cultural, and pharmacological effects, Temperature 3 (2016): 39-40.

20. Szolcsányi J. Capsaicin and sensory neurones: a historical perspective. In: Abdel-Salam OME. (ed.) Capsaicin as a Therapeutic Molecule. Progress in Drug Research 68 (2014): 1-37.

21. Nagy I, Friston D, Valente JS, et al. Pharmacology of the capsaicin receptor, transient receptor potential vanilloid type-1 ion channel. In: Abdel-Salam OME. Capsaicin as a Therapeutic Molecule. Progress in Drug Research, Springer, Basel. 68 (2014): 39-76.

22. Abdel-Salam OME, Mózsik Gy, Szolcsányi J. Studies on the effect of intragastric capsaicin on gastric ulcer and on the prostacyclin-induced cytoprotection in rats. Pharmacol. Res 32 (1995): 209-215.

23. Mózsik Gy, Past T, Habon T, et al. Capsaicin is a New Gastrointestinal Mucosal Protecting Drug Candidate in Humans - Pharmaceutical Development and Production Based on Clinical Pharmacology. In: Clinical Pharmacological Approach of Capsaicin Action in GI Tract. In: Capsaicin - Sensitive Neural Afferentation and the Gastrointestinal Tract: from Bench to Bedside". Mózsik Gy, Abdel- Salam OME, Takeuchi K. ISBN 978-953-51-1631-8 (2014).

24. Abdel-Salam OME, Sleem AA, Hassan NS, et al. Capsaicin ameliorates hepatic injury caused by carbon tetrachloride in the rat. J Pharmacol Toxicol 1 (2006): 147-156.

25. Pegorini S, Braida D, Verzoni C, et al. Capsaicin exhibits neuroprotective effects in a model of transient global cerebral ischemia in Mongolian gerbils. Br J Pharmacol 144 (2005): 727-735.

26. Chung YC, Baek JY, Kim SR, et al. Capsaicin prevents degeneration of dopamine neurons by inhibiting glial activation and oxidative stress in the MPTP model of Parkinson's disease. Exp Mol Med 49 (2017): e298. 
27. Betarbet R, Sherer TB, MacKenzie G, et al. Chronic systemic pesticide exposure reproduces features of Parkinson's disease. Nat Neurosci 3 (2000): 1301-1306.

28. Sherer TB, Kim JH, Betarbet R, et al. Subcutaneous rotenone exposure causes highly selective dopaminergic degeneration and alpha-synuclein aggregation. Exp Neurol 179 (2003): 9-16.

29. Sherer TB, Betarbet R, Testa CM, et al. Mechanism of toxicity in rotenone models of Parkinson's disease. J Neurosci 23 (2003): 10756-10764.

30. Li N, Ragheb K, Lawler G, et al. Mitochondrial complex I inhibitor rotenone induces apoptosis through enhancing mitochondrial reactive oxygen species production. J Biol Chem 278 (2003): 8516-8525.

31. Testa CM, Sherer TB, Greenamyre JT. Rotenone induces oxidative stress and dopaminergic neuron damage in organotypic substantia nigra cultures. Brain Res Mol Brain Res 134 (2005): 109-118.

32. Xiong ZK, Lang J, Xu G, et al. Excessive levels of nitric oxide in rat model of Parkinson's disease induced by rotenone. Exp Ther Med 9 (2015): 553-558.

33. Abdel-Salam OME, Youness ER, Mohammed NA, et al. The effect of 2,4-dinitrophenol on oxidative stress and neuronal damage in rat brain induced by systemic rotenone injection. Reactive Oxygen Species 3 (2017): 135-147.

34. Abdel-Salam OME, Youness ER, Mohammed NA, et al. Brilliant blue G protects against rotenone-induced neuronal damage in the rat brain. Reactive Oxygen Species 4 (2017): 336-350.

35. Abdel-Salam OME, Omara EA, Youness ER, et al. Rotenone-induced nigrostriatal toxicity is reduced by methylene blue. J Neurorestoratol 2 (2014): 65-80.

36. Abdel-Salam OME, Mohammed NA, Youness ER, et al. Cerebrolysin protects against rotenone-induced oxidative stress and neurodegeneration. J Neurorestoratol 2 (2014): 47-63.

37. Abdel-Salam OME, Youness ER, Ahmed NA, et al. Bougainvillea spectabilis flowers extract protects against the rotenone-induced toxicity. Asian Pacific Journal of Tropical Medicine 10 (2017): 478-490.

38. Nair V, Turner GA. The thiobarbituric acid test for lipid peroxidation: structure of the adduct with malondialdehyde. Lipids 19 (1984): 804-805.

39. Moshage H, Kok B, Huizenga JR, et al. Nitrite and nitrate determinations in plasma: a critical evaluation. Clin Chem 41 (1995): 892-896.

40. Ellman GL. Tissue sulfhydryl groups. Arch Biochem Biophys 82 (1959): 70-77.

41. Eckerson HW, Wyte CM, La Du BN. The human serum paraoxonase/arylesterase polymorphism. Am J Hum Genet 35 (1983): 1126-1138.

42. Ellman GL, Courtney KD, Andres V Jr, et al. A new and rapid colorimetric determination of acetylcholinesterase activity. Biochem Pharmacol 7 (1961): 88-95.

43. Halliwell B. Biochemistry of oxidative stress. Biochem Soc Trans 35 (2007): 1147-1150.

44. Mytilineou C, Kramer BC, Yabut JA. Glutathione depletion and oxidative stress. Parkinsonism Relat Disord 8 (2002): 385-387.

45. Radad K, Rausch WD, Gille G. Rotenone induces cell death in primary dopaminergic culture by increasing ROS production and inhibiting mitochondrial respiration. Neurochem Int 49 (2006): 379-386. 
46. Abdel-Salam OME, Medhat D, Sleem AA, et al. Neuroprotection by montelukast against rotenone-induced rat brain damage. Reactive Oxygen Species 5 (2018): 209-219.

47. Ibrahim NA, Abdel-Salam OM, Khadrawy YA, et al. Non-steroidal anti-inflammatory drugs and vitamin c in the rotenone induced nigrostriatal damage in mice. Eur J Clin Biomed Sci 3 (2017): 67-79.

48. Watanabe H, Muramatsu Y, Kurosaki R, et al. Protective effects of neuronal nitric oxide synthase inhibitor in mouse brain against MPTP neurotoxicity: an immunohistological study. Eur Neuropsychopharmacol 14 (2004): 93-104.

49. He Y, Imam SZ, Dong Z, et al. Role of nitric oxide in rotenone-induced nigro-striatal injury. J Neurochem 86 (2003): 1338-1345.

50. Wink DA, Feelisch M, Vodovotz Y, et al. The Chemical Biology of Nitric Oxide. In: Reactive Oxygen Species in Biological Systems, edited by Gilbert and Colton. Kluwer Academic / PlenumPublishers, New York (1999): 245-291.

51. Weidinger A, Kozlov AV. Biological activities of reactive oxygen and nitrogen species: oxidative stress versus signal transduction. Biomolecules 5 (2015): 472-484.

52. Garry PS, Ezra M, Rowlanda MJ, et al. The role of the nitric oxide pathway in brain injury and its treatment - From bench to bedside. Experimental Neurology 263 (2015): 235-243.

53. Joshi YB, Praticò D. The 5-lipoxygenase pathway: oxidative and inflammatory contributions to the Alzheimer's disease phenotype. Frontiers in Cellular Neuroscience 8 (2015): 1-8.

54. Gelosa P, Colazzo F, Tremoli E, et al. Cysteinyl leukotrienes as potential pharmacological targets for cerebral diseases. Mediators of Inflammation (2017).

55. Zhang XY, Chen L, Yang Y, et al. Regulation of rotenone-induced microglial activation by 5-lipoxygenase and cysteinyl leukotriene receptor 1. Brain Res 1572 (2014): 59-71.

56. Wang Y, Zhang X, Li C, et al. Involvement of 5-lipoxygenase/cysteinyl leukotriene receptor 1 in rotenoneand MPP+-induced BV2 microglial activation. Molecular Neurodegeneration 7 (2012): S24.

57. Kulka M. A review of paraoxonase 1 properties and diagnostic applications. Pol J Vet Sci 19 (2016): 225232 .

58. Ng DS, Chu T, Esposito B, et al. Paraoxonase-1 deficiency in mice predisposes to vascular inflammation, oxidative stress, and thrombogenicity in the absence of hyperlipidemia. Cardiovasc Pathol 17 (2008): 226232.

59. Menini T, Gugliucci A. Paraoxonase 1 in neurological disorders. Redox Rep 19 (2014): 49-58.

60. Nguyen SD, Sok DE. Preferential inhibition of paraoxonase activity of human paraoxonase 1 by negatively charged lipids. J Lipid Res 45 (2004): 2211-2220.

61. Abdel-Salam OME. The Rotenone model of Parkinson's disease in studying the mechanisms of nigrostriatal cell death. J Pharma Pharmacovigilance 1 (2015): 007.

62. Richter F, Hamann M, Richter A. Chronic rotenone treatment induces behavioral effects but no pathological signs of parkinsonism in mice. J Neurosci Res 85 (2007): 681-691.

63. Frandsen JR, Narayanasamy P. Neuroprotection through flavonoid: Enhancement of the glyoxalase pathway. Redox Biol 14 (2018): 465-473. 
64. Bagli E, Goussia A, Moschos MM, et al. Natural compounds and neuroprotection: mechanisms of action and novel delivery systems. In Vivo 30 (2016): 535-547.

65. Evangelista S. Capsaicin receptor as target of calcitonin gene-related peptide in the gut. In: Abdel-Salam OME. Capsaicin as a Therapeutic Molecule. Progress in Drug Research. Springer, Basel 68 (2014): 259276.

Citation: Omar M.E. Abdel-Salam, Amany A Sleem, Eman R. Youness, Noha N. Yassen, Nermeen Shaffie, Sayed A. El-Toumy. Capsicum Protects Against Rotenone-Induced Toxicity in Mice Brain Via Reduced Oxidative Stress and 5-Lipoxygenase Activation. J Pharm Pharmacol Res 2 (2018): 060-075. 